\title{
Why the new inhalation agents?
}

The pharmacokinetic features of new intravenous (i.v.) anaesthetic drugs permit a rapid equilibration between plasma and receptor site concentrations which enables a rapid onset. Furthermore, they have large distribution volumes and high metabolic clearances which lead to a rapid decrease in plasma concentration and produce a rapid recovery after they are discontinued. These new i.v. agents in combination with new techniques (computerized i.v. pumps) also allow a precise control over the depth of anaesthesia so that total i.v. anaesthesia has the same advantages as inhalation anaesthesia in this regard. Inhalation anaesthesia nevertheless remains very popular due to the fact that many anaesthetists are conversant with this technique but are not familiar with the i.v. technique. In times of day-care surgery and pressures on costs it is important to improve safety of anaesthesia, to avoid long lasting effects of agents and to reduce the recovery time from anaesthesia. The ideal volatile anaesthetic should be inert, independent of metabolism and nothing should be left in the organism at the end of anaesthesia. The following criteria should be fulfilled:

- hypnotic, analgesic and muscle relaxing properties;

- quick and smooth induction and recovery from anaesthesia and precise control over delivery of anaesthesia;

- high safety margins and minimal side effects on organ systems;

- high stability in vitro and in vivo and not inflammable;

- odourless or pleasant smell;

- environmentally friendly.

The older inhalational agents halothane, enflurane and isoflurane do not meet these criteria sufficiently, so there was a need for improved agents. Desflurane and sevoflurane have a low solubility in blood and tissues and thus possess favourable kinetic properties which allow a precise control over delivery of

Accepted July 1999 anaesthesia 11. Sevoflurane lacks pungency and airway irritability so that induction of anaesthesia can be easily achieved in children and adults. Cardiovascular and respiratory events are reduced compared with halothane. Intravenous agents such as propofol cause pain on injection which can be avoided by inhalational induction. Sevoflurane has replaced halothane, especially in children, in modern anaesthesia.

Up to $5 \%$ of inhaled sevoflurane is metabolized in the human body 2]. Increased serum fluoride concentrations have been observed. Compared with methoxyflurane, however, renal involvement has not been proved due to less intrarenal fluoride generation [3,4]. Desflurane is more pungent than the other currently available volatile agents and is not suitable for induction of anaesthesia. It is less soluble than sevoflurane. Thus a more rapid increase in alveolar concentration is achieved and an earlier emergence from anaesthesia is observed. Only $0.02 \%$ of the agent is metabolized and this makes it favourable for prolonged maintenance of anaesthesia [1]. Rapid increase in the inspiratory concentration of desflurane may induce tachycardia and hypertension which is due to sympathic activation. Both agents are less potent than the old volatiles and increased inspiratory concentrations have to be applied.

Low flow anaesthesia is an effective technique for minimizing costs and pollution, preserving heat and to humidify the inspired gas. Desflurane can be used in low-flow or closed-circle systems. Desflurane, isoflurane and enflurane all react with dry carbon dioxide absorber material forming carbon monoxide [5]. Reduction of the fresh gas flow avoids drying of the absorber lime and thus contributes to safety in addition to regular changes of the material. Sevoflurane is degraded by carbon dioxide absorbents generating a vinylhalide called compound A. Compound $A$ is known to induce renal toxicity in rats but in humans data concerning renal toxicity are conflicting $\$-11$. Inspiratory concentrations of compound $A$ increase with increasing concentrations of 
sevoflurane and with a reduction in the fresh gas flow. Absorber material, temperature, $\mathrm{CO}_{2}$ production and construction of the anaesthetic circuit further contribute to compound A generation. Although there are no restrictions in the European Union concerning fresh gas flows in sevoflurane anaesthesia, one should be cautious for the use of prolonged sevoflurane administration at high inspiratory concentrations with fresh gas flows below $1 \mathrm{~L} \mathrm{~min}^{-1}$ until there are better data with respect to potential inspiratory compound A concentrations and their toxicological impact.

The ideal volatile anaesthetic would be xenon 12 13. It is inert, it does not react with other agents and it is not metabolized. Its extremely low blood:gas solubility and its analgesic properties suggests that its widespread use could replace nitrous oxide and the volatile anaesthetics in many clinical situations. Unfortunately xenon is extremely expensive due to the requirement for its isolation from limited natural resources. Application of xenon in a closed-circuit anaesthetic system might be a future form of inhalational anaesthesia and one way to avoid environmental pollution by sparing nitrous oxide, halogenated carbons and i.v. anaesthetics.

\section{Goeters and H. Van Aken Klinik und Poliklinik für,} Anästhesiologie und operative Intensivmedizin der, Westfälischen Wilhelms-Universität Münster, Albert-Schweitzer-Str.33, 48149 Münster, Germany

\section{References}

1 Scholz J, Tonner PH. Desfluran und Sevofluran. Eine Zwischenbilanz Anaesthesist 1997; 46: 816-825.

2 Kharasch ED, Karol MD, Lanni C, Sawchuk R. Clinical sevoflurane metabolism and disposition. I. Sevoflurane and metabolite pharmacokinetics. Anesthesiology 1995; 82: 1369-1378.

3 Kharasch ED, Thummel KE. Identification of cytochrome
P450 2E1 as the predominant enzyme catalyzing human liver microsomal defluorination of sevoflurane, isoflurane, and methoxyflurane. Anesthesiology 1993; 79: 795-807.

4 Kharasch ED, Hankins DC, Thummel KE. Human kidney methoxyflurane and sevoflurane metabolism. Anesthesiology 1995; 82: 689-699.

5 Fang ZX, Eger IIEl, Laster MJ, Chortkoff BS, Kandel L, lonescu P. Carbon monoxide production from degradation of desflurane, enflurane, isoflurane, halothane and sevoflurane by soda lime and baralyme. Anesth Analg 1995; 80: 1187-1193.

6 Karasch ED, Frink EJ Jr, Zager R, Bowdle TA, Artru A, Nogami WM. Assessment of low-flow sevoflurane and isoflurane effects on renal function using sensitive markers of tubular toxicity. Anesthesiology 1997; 86: 1238-1253.

7 Bito $\mathrm{H}$, Ikeuchi Y, Ikeda K. Effects of low-flow sevoflurane on renal function. Comparison with high-flow sevoflurane and low-flow isoflurane anesthesia. Anesthesiology 1997; 86: 1231-1237.

8 Higuchi $\mathrm{H}$, Sumita S, Wada $\mathrm{H}$ et al. Effects of sevoflurane and isoflurane on renal function and on possible markers of nephrotoxicity. Anesthesiology 1998; 89: 307-322.

9 Eger IIEI, Koblin DD, Bowland T et al. Nephrotoxicity of sevoflurane versus desflurane anesthesia in volunteers. Anesth Analg 1997; 84: 160-168.

10 Eger IIEl, Gong D, Koblin DD et al. Dose-related biochemical markers of renal injury after sevoflurane versus desflurane anesthesia in volunteers. Anesth Analg 1997; 85: 1154-1163.

11 Ebert TJ, Frink EJ Jr, Kharasch ED. Absence of biochemical evidence for renal and hepathic dysfunction after 8 hours of 1.25 minimum alveolar concentration sevoflurane anesthesia in volunteers. Anesthesiology 1998; 88: 601-610.

12 Goto T, Saito H, Shinkai M, Nakata Y, Ichinose F, Morita S. Xenon provides faster emergence from anaesthesia than does nitrous oxide-sevoflurane or nitrous oxideisoflurane. Anesthesiology 1997; 86: 1273-1278.

13 Goto T, Saito H, Nakata Y, Uezono S, Ichinose F, Morita S. Emergence times from xenon anaesthesia are independent of the duration of anaesthesia. $\mathrm{Br} J$ Anaesth 1997; 79: 595-599. 